\title{
OS LIMITES NA FORMAÇÃO DE PROFESSORES DE LETRAS ESTRANGEIRAS DA UFPA PARA ATUAR NA EDUCAÇÃO INCLUSIVA: UMA ANÁLISE CURRICULAR
}

Jéssica da Silva Miranda

Discente do curso de Letras- Alemão da Universidade Federal do Pará (UFPA). E-mail: jessica_giovanna97@ hotmail.com.

\section{RESUMO}

Este estudo resulta do seguinte questionamento: a implantação das políticas educacionais inclusivas tem alcançado a formação dos professores dos cursos de Letras Estrangeiras Modernas da Universidade Federal do Pará (UFPA). Nesse sentido, este estudo tem por objetivo analisar as perspectivas de inclusão no currículo do curso de Letras: Alemão, Espanhol, Francês e Inglês da Faculdade de Letras Estrangeiras Modernas da UFPA. Após fazer a análise deste currículo, identifiquei que apenas a disciplina de Libras apresenta um conteúdo que aproxima as discussões para uma perspectiva de formação inclusiva.

PALAVRAS-CHAVE: Letras Estrangeiras. Educação Inclusiva. Formação.

\section{THE LIMITS IN TRAINING TEACHERS OF FOREIGN LETTERS AT UFPA TO WORK IN INCLUSIVE EDUCATION: A CURRICULAR ANALYSIS}

\begin{abstract}
This study results from the following question: the implementation of inclusive educational policies has reached the training of teachers in the courses of Modern Foreign Languages at the Federal University of Pará (UFPA). In this sense, this study aims to analyze the prospects for inclusion in the curriculum of the Literature course: German, Spanish, French and English at the Faculty of Modern Foreign Languages at UFPA. After analyzing this curriculum, I identified that only the Libras discipline has content that brings discussions
\end{abstract}


closer to an inclusive education perspective.

KEYWORDS: Foreign Letters. Inclusive education. Formation.

\section{INTRODUÇÃ̃o}

Este estudo originou-se a partir da minha condição de graduanda no curso de Letras/Alemão, que está me proporcionando a experiência de estagiar na educação especial inclusiva em uma escola da rede pública estadual, aonde venho percebendo os desafios a serem enfrentados na prática pedagógica inclusiva.

Com isso, faço o seguinte questionamento: a implantação das políticas educacionais inclusivas tem alcançado a formação dos professores dos cursos de Letras Estrangeiras Modernas da Universidade Federal do Pará (UFPA)? Nesse sentido, este estudo tem por objetivo analisar as perspectivas de inclusão no currículo do curso de Letras: Alemão, Espanhol, Francês e Inglês da Faculdade de Letras Estrangeiras Modernas da UFPA.

O direito à educação é consubstanciado na Constituição Federal de 1988 e reafirmado na Lei n. 9394/96 de Diretrizes e Bases da Educação Brasileira. Apesar deste direito constar no documento de maior peso jurídico da sociedade, a prática social no dia a dia nos revela que a negação deste direito é comum em diversas situações, uma delas reside na falta de consistência na formação de professores para atuar com alunos deficientes em sala de aula, que no geral acaba resultando em uma falha no atendimento destes alunos, que por muito tempo permaneceram invisibilizados ou segregados nas políticas públicas educacionais.

Afinal, foi somente a partir da década de 1990 que houve uma preocupação com a formação de todos os professores, e não mais de um pequeno grupo destinado a atender os alunos com deficiência nos moldes segregacionista.

Conforme a Resolução CNE/CEB n. 2/2001 que institui Diretrizes Nacionais para a Educação Especial na Educação Básica, a educação inclusiva corresponde:

[...] a garantia, a todos, do acesso contínuo ao espaço comum da vida em sociedade, sociedade essa que deve estar orientada por relações de acolhimento à diversidade humana, de aceitação das diferenças individuais, de esforço coletivo na equiparação de oportunidades de desenvolvimento, com qualidade, em todas as dimensões da vida (BRASIL, 2001, p. 39-40).

De acordo com os dados do Censo Escolar de 2018, é crescente o número de matrículas 
de estudantes com deficiências. Estes dados revelam a presença de 1,2 milhão de alunos com deficiência, altas habilidades e transtornos globais do desenvolvimento, e destes 97,3\% estavam nas classes comuns da rede pública.

Estes dados do Censo 2018 demonstram o tamanho do desafio das escolas, em especial da rede pública, para possibilitar o acesso e permanência destes alunos com deficiência, em vista de diversos aspectos: material didático, infraestrutura e formação que prepare os professores para saber lidar com os desafios da inclusão.

\section{EDUCAÇÃO INCLUSIVA}

A construção de uma educação inclusiva é resultado de esforços para por fim na segregação que ocorria no sistema de ensino até o início do século XXI, no qual os alunos com deficiência eram separados dos alunos das turmas regulares, o que ocorria devido à existência da escola regular e da escola especial. E nesse sentido,

A Educação Inclusiva compreende a Educação especial dentro da escola regular e transforma a escola em um espaço para todos. Ela favorece a diversidade na medida em que considera que todos os alunos podem ter necessidades especiais em algum momento de sua vida escolar (ALONSO, 2013 , n.p).

É válido ressaltar que esse conceito de Educação inclusiva emerge a partir de 1994 com a Declaração de Salamanca que versa sobre a necessidade de incluir as crianças com deficiências no processo de ensino regular. E isto, de certo modo, mostra uma superação em nossa cultura, de não mais excluir o diferente, mas aceitar a diversidade e a deficiência do outro. Mas é claro que isso não ocorre de uma hora para outra, mas os documentos institucionais se apresentam como mediação nesse processo de construção de uma sociedade inclusiva.

Atualmente no Brasil temos uma política de educação inclusiva assegurada nos seguintes documentos: Lei9394/96 de Diretrizes e Bases da Educação (BRASIL, 1996), Diretrizes Nacionais para Educação Especial na Educação Básica (BRASIL, 2001) e Política Nacional de Educação Especial na perspectiva inclusiva (BRASIL, 2008).

Mas apesar destes documentos terem possibilitados o acesso das pessoas com deficiência ao ensino regular e contribuído para o processo de inclusão, tem sido lenta a absorção destas políticas na formação dos professores, o que gera dificuldades no atendimento 
desses alunos devido às fragilidades na formação dos professores, que não tem sido suficiente para abarcar as demandas que esse atendimento necessita.

E por outro lado, os alunos sofrem diante dessa falta de formação dos professores, visto que, por vezes a formação desses alunos fica restrita apenas no âmbito da socialização, quando na realidade a educação deve auxiliá-los no desenvolvimento de suas potencialidades.

\title{
3 FORMAÇÃO DE PROFESSORES
}

Como já observado, a democratização do acesso ocorrida com a entrada das pessoas com deficiências na escola suscita mudanças educacionais e hoje um dos grandes desafios da educação inclusiva está na formação dos professores que irão atuar diretamente em sala de aula para dar efetividade à inclusão, conforme consta nos documentos legais (VITALIANO; DALL“ACQUA, 2012).

Vitaliano e Dall' Acqua (2012) demonstram que há uma fragilidade na formação dos professores e que ela ocorre devido às políticas educacionais inclusivas serem recentes, da década de 1990. Os autores apontam também que muitos cursos de graduação não ofertam disciplinas que tratem do tema inclusão.

Sobre este ponto vale ressaltar que desde 2005 é obrigatória a disciplina de Libras nos cursos de licenciatura conforme consta no Art. $3^{\circ}$ do decreto $n^{\circ} 5.626$ :

\begin{abstract}
Art. $3^{\circ}$ A Libras deve ser inserida como disciplina curricular obrigatória nos cursos de formação de professores para o exercício do magistério, em nível médio e superior, e nos cursos de Fonoaudiologia, de instituições de ensino, públicas e privadas, do sistema federal de ensino e dos sistemas de ensino dos Estados, do Distrito Federal e dos Municípios (BRASIL, 2005).
\end{abstract}

É claro que a ideia posta no decreto não se concretizou de uma hora pra outra, pois afinal, havia profissionais suficientes para suprir de imediato essa demanda que a formação destes professores impunha? Obviamente que não, pois até então não havia políticas robustas de capacitação para a inclusão. Ou seja, para poder incluir na escola, necessita-se de uma adaptação dos currículos da formação inicial de professores. E para Mendes (2004, p. 227), "uma política de formação de professores é um dos pilares para a construção da inclusão escolar".

\section{ANÁLISE DO CURRÍCULO}

A Resolução CNE/CEB nº 02/2015 que define as Diretrizes Curriculares Nacionais 
para a formação inicial em nível superior (cursos de licenciatura, cursos de formação pedagógica para graduados e cursos de segunda licenciatura) e para a formação continuada, ao tratar do currículo dos cursos de licenciatura aponta, dentre outros elementos, que:

$\S 2^{\circ}$ Os cursos de formação deverão garantir nos currículos conteúdos específicos da respectiva área de conhecimento ou interdisciplinares, seus fundamentos e metodologias, bem como conteúdos relacionados aos fundamentos da educação, formação na área de políticas públicas e gestão da educação, seus fundamentos e metodologias, direitos humanos, diversidades étnico-racial, de gênero, sexual, religiosa, de faixa geracional, Língua Brasileira de Sinais (Libras), educação especial e direitos educacionais de adolescentes e jovens em cumprimento de medidas socioeducativas. (BRASIL, 2015, grifo nosso).

Este é o único ponto do capítulo $\mathrm{V}$, que trata sobre o currículo da formação inicial, que menciona elementos da educação inclusiva. E como podemos perceber o texto é bem sucinto ao apontar os conteúdos que incidem em uma formação para educação inclusiva, o que acredito não ser o suficiente para propor uma formação consistente aos professores que vão enfrentar uma realidade complexa no dia a dia de uma escola que vive a realidade da inclusão.

Ao analisar essas diretrizes e relacionar com o currículo dos Cursos de Licenciatura em Letras da Universidade Federal do Pará podemos observar que os cursos não oferecem, no que diz respeito a uma formação para inclusão, nada além daquilo proposto nestas diretrizes, pois a única disciplina, durante os 8/10 semestres dos cursos, que abrange temas da educação inclusiva é a disciplina de Libras.

A partir desta constatação, vem o seguinte questionamento: esta única disciplina seria capaz de capacitar um professor para atuar com a diversidade de situações e possibilidades que surgem com a educação inclusiva no espaço de atuação de um professor(a) de Letras Língua Estrangeira?

O que verifiquei na prática durante o estágio em uma escola pública, é que faltam elementos na minha formação que possam fundamentar, dar base, mesmo que mínima, para que um aluno que passa por esta formação possa ter conhecimentos básicos para lidar com as situações que a educação inclusiva demanda em sala de aula.

\section{CONSIDERAÇÕES FINAIS}

$\mathrm{O}$ atendimento e qualidade da educação estão vinculados à qualidade da formação de professores que atendem e que irão atender os estudantes, em especial aqueles com 
deficiências que demandam um esforço maior por apresentarem suas especificidades. Portanto, ações que colaborem para uma maior consistência na formação superior, inicial e continuada, de todos os professores são essenciais para que se efetivem as políticas educacionais inclusivas.

Talvez estejamos ainda vivenciando um período de adaptação, e podemos observar que conseguimos avanços até aqui. Mas acredito que nesse quesito da formação dos professores, isso demanda um maior investimento tanto em formação inicial quanto continuada para os professores, devendo haver uma maior flexibilização no currículo.

\section{REFERÊNCIAS BIBLIOGRÁFICAS}

ALONSO, Daniela. Os desafios da Educação inclusiva: foco nas redes de apoio. Nova Escola. 01 fev. 2013. Disponível em: https://novaescola.org.br/conteudo/554/ os-desafios-da-educacao-inclusivafoco-nas-redes-de-apoio. Acesso em: 29 ago. 2019.

BRASIL. Ministério de Educação e Cultura. LDB - Lei $n^{o}$ 9394/96, de 20 de dezembro de 1996. Estabelece as diretrizes e bases da Educação Nacional. Brasília: MEC, 1996.

Educação. $\quad \begin{gathered}\text { Conselho Nacional de } \\ \text { Resolução }\end{gathered}$ n.2/2001, de 11 set. 2001. Institui Diretrizes Nacionais para a Educação Especial na Educação Básica. Brasília: Presidência da República, Casa Civil, 2001.

Decreto $\mathrm{n}^{\circ} 5.626$, de 22 de dezembro de 2005. Regulamenta a Lei $n^{\circ}$ 10.436, de 24 de abril de 2002, que dispõe sobrea Língua Brasileira de Sinais - Libras, e o art. 18 da Lei $\mathrm{n}^{\circ}$ 10.098, de 19 de dezembro de 2000. Diário Oficial da União, Brasília,23 dez. 2005.

. Política Nacional de
Educação Especial na Perspectiva da Educação Inclusiva. Brasília: MEC: SEESP, de janeiro de 2008.

$\begin{array}{cl}\text { Educação. } & \begin{array}{l}\text { Conselho Nacional de } \\ \text { Define as Diretrizes }\end{array}\end{array}$ Curriculares Nacionais

para a formação inicial em nível superior (cursos de licenciatura, cursos de formação pedagógica para graduados e cursos de segunda licenciatura) e para a formação continuada. Resolução CNE/CP n. 02/2015, de $1^{\circ}$ de julho de 2015. Brasília, Diário Oficial [da]República Federativa do Brasil, seção 1, n. 124, p. 8-12, 02 de julho de 2015.

MENDES, E. G. Construindo um "lócus" de pesquisas sobre inclusão escolar. In: MENDES, E.G; ALMEIDA, M. A; WILLIAMS, L. C. de. Temas em educação especial: avanços recentes. São Carlos: EdUFSCAR, pp.221-230, 2004.

VITALIANO, C. R; DALL ${ }^{c e}$ ACQUA, M. J. C. Análise das diretrizes curriculares dos cursos de Licenciatura em relação à formação de professores para inclusão de alunos com necessidades especiais. Revista Teias, v. 13 , n. 27 , p. 103-121, jan - abril, 2012. 
MIRANDA, J. S. Os Limites na Formação de Professores de Letras Estrangeiras da UFPA Para Atuar na Educação Inclusiva: Uma Análise Curricular. Complexitas - Rev. Fil. Tem. Belém, v. 4, n. 1, p. 66-72, jan.jun. 2019. Disponível em: http://www.periodicos.ufpa.br/index.php/complexitas/article/view/8044>. Acesso em: 30 de janeiro de 2020. 